patients, 7.0\%), and others (19 patients, 4.03\%). Among the 630 procedures, 230 procedures $(36.51 \%)$ had no positive finding in the intestine, and the positive finding was more often through the anal route ( $60.88 \%$ VS $52 \%, \mathrm{P}<0.001)$. In all, 333 procedures $(52.86 \%)$ detected erosion, ulcer, inflammation, or scar, 16 procedures $(2.54 \%)$ detected polyps, 19 procedures $(3.02 \%)$ detected tumor or mass, 2 procedures $(0.32 \%)$ detected vascular anomaly, 16 procedures $(2.54 \%)$ detected diverticulum, 47 procedures $(7.46 \%)$ detected strictures, 1 procedure $(0.16 \%)$ detected parasite, 19 procedures (3.02\%) detected flat lesions, white spot, or yellow spot, and 1 procedure $(0.16 \%)$ detected blue colored mucosa. The therapeutic interventions included biopsy (109 procedures, $17.30 \%)$, polypectomy (10 procedures, $1.59 \%$ ) extraction of retained capsule endoscopy (2 procedures, $0.32 \%)$, balloon dilation ( 2 procedures, $0.32 \%$ ) localization for further surgery (1 procedure, $0.16 \%$ ), and endoscopic hemostasis (1 procedure, $0.16 \%)$. Just a number of mild to moderate complications occurred, which included bradycardia (1 patient, $0.21 \%$ ), acute cholangitis (1 patient, $0.21 \%)$, abdominal discomfort (10 patient, $2.12 \%$ ), sore throat (4 patient, $0.85 \%$ ), bloody watery stool (1 patient, 0.21\%), chills and fever (1 patient, $0.21 \%$ ).

Conclusions DBE is helpful and safe for diagnosing and treating some intestinal disease.

\section{IDDF2019-ABS-0201 THE CLINICAL ANALYSIS OF ENDOSCOPIC TREATMENT FOR NON-VARICOSE UPPER GASTROINTESTINAL BLEEDING}

Xiaodong Chen*, Jiachuan Wu, Ruiyan Chen, Xiaogiao Yang, Lifang Ye. Guangdong second provincial general hospital, China

\subsection{6/gutjnl-2019-IDDFabstracts. 195}

Background To investigate the application value of endoscopic hemostatic therapy in treating nonvariceal upper gastrointestinal bleeding (NVUGIB).

Methods 90 patients with NVUGIB were selected in this research. According to the order of admission, 45 patients in the conventional group (January to June 2017) and 45 patients in the endoscopic group (July to December 2017) were respectively treated with conventional hemostasis and endoscopic hemostasis. Compare the therapeutic effects of the two treatment regimens.

Results The hemostatic efficiency of the endoscopic group was $97.78 \%$ higher than that of the conventional group $\left(X^{2}=6.352\right.$, $P<0.05)$. The length of hospital stay $9.56 \mathrm{~d}$ was shorter than that in the conventional group $15.94 \mathrm{~d},(\mathrm{t}=14.005, \mathrm{P}<0.05)$. The rate of rebleeding was $2.22 \%$ lower than that of the control group, $\left(X^{2}=8.607, P<0.05\right)$.

Conclusions Endoscopic hemostasis for patients with NVUGIB can improve hemostasis efficiency, shorten the length of hospital stay, and effectively prevent re-bleeding.

\section{IDDF2019-ABS-0205 A RARE CASE OF URETEROILEAL FISTULA PRESENTING FROM INDIAN TERTIARY CARE CENTER AFTER LAPAROSCOPIC CHOELECYSTECTOMY}

Vijay Sharma*, Richa Sharma. Regional institute of health medicine and research, Jaipur, Rajasthan, India

10.1136/gutjnl-2019-IDDFabstracts. 196
Background We present a very rare case of a sixteen-year-old girl who reported to Gastroenterology, after earlier visits at Manipal hospital Jaipur with a history of chronic diarrhea. The watery diarrhoea was there for 3 months, and it started after laparoscopic choelecystectomy. It had no relation to food intake, all times of day, not relieving with medication. Normal duodenoscopy and full colonoscopy. No ileoscopy has done.

Methods sixteen-year-old girl was managed by surgeon and gastroenterologist as bile acid diarrhoea, treated conservatively, bile acid binding agent did not work, course of anthelminthic, antidiarrheal, modified diet did not work, there was no weight loss, family was distressed, due to watery diarrhoea day and night, unable to sleep, with pain in right iliac fossa.

As we suspected some kind of spurious diarrhea due to the surgical complication, we sent stool sample of the patient for stool urea and stool creatinine measurement, stool creatinine was $30 \mathrm{mg} / \mathrm{dl}$ and stool urea was $700 \mathrm{mg} / \mathrm{dl}$. It supported the diagnosis of spurious diarrhea. The patient underwent contrast-enhanced Compound tomography of the abdomen; it revealed communication of ileum lower end with right ureter lower one third. Now the diagnosis of Ureteroileal fistula was confirmed. (figure 1)

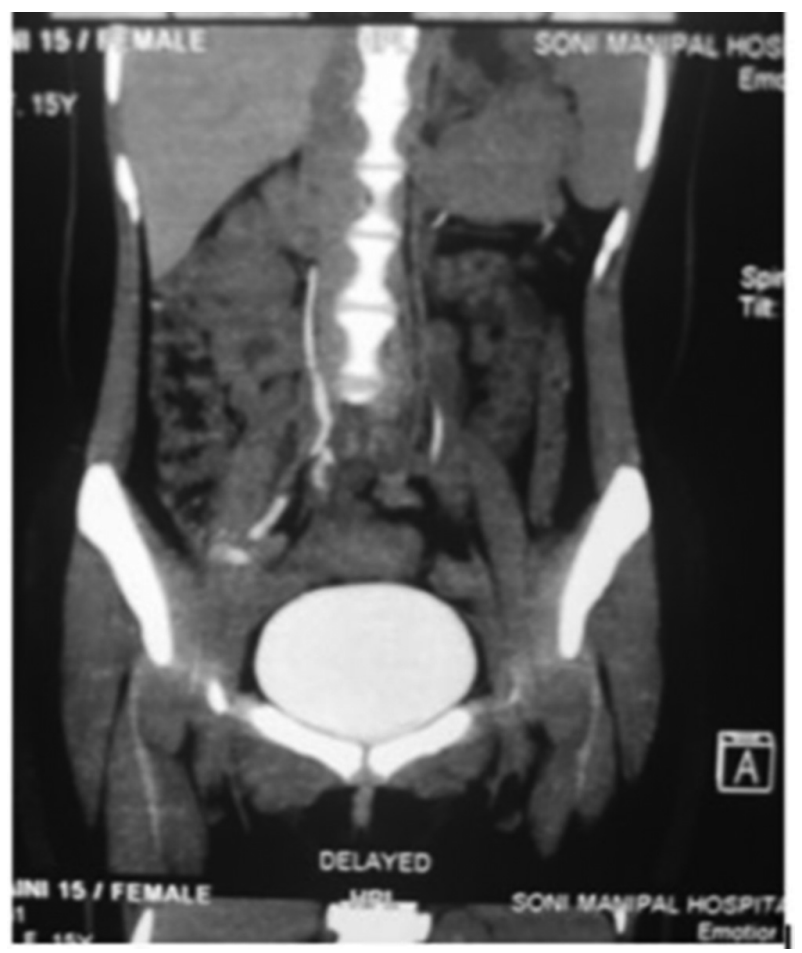

Abstract IDDF2019-ABS-0205 Figure 1 Ureteroilial fistula clearly visible at the lower one-third of the right ureter

Results The patient was referred to the Urologist, she underwent cystoscopy, urinary bladder was normal, right ureteric stent was placed, Foleys catheter placed to decrease pressure in the bladder for one month, diarrhoea stopped, patient improved, later on, follow up after removal of Foleys catheter she was doing fine and she was satisfied with the treatment. Discussion Fistula's which communicate between the Urinary system and intestine are rare, and among them, fistulas that involve the urinary and intestinal tracts means Vesicointestinal fistulas are the most common, vesicoureteric fistulas are 